\title{
Prevalence of multi-gastrointestinal infections with helminth, protozoan and Campylobacter spp. in Guatemalan children
}

\author{
Lauritz A. Jensen ${ }^{1}$, Jerry W. Marlin ${ }^{2}$, David D. Dyck ${ }^{2}$, Harold E. Laubach ${ }^{3}$ \\ ${ }^{1}$ Department of Microbiology and Immunology, Arizona College of Osteopathic Medicine, Midwestern University, Glendale, \\ Arizona 85308 \\ ${ }^{2}$ Department of Biochemistry, Kansas City University of Medicine and Biosciences, Kansas City, Missouri 64106 \\ ${ }^{3}$ Department of Microbiology, College of Medical Sciences, Health Professions Division, Nova Southeastern University, Fort \\ Lauderdale, Florida 33328
}

\begin{abstract}
Background: The prevalence of multi-infections with helminthes, protozoans and Campylobacter spp. in Guatemalan children is a reflection of differences in the risk factors related to pathogen transmission.

Methodology: Two hundred and eighty-nine fecal samples were collected from children of the Guatemalan highlands and patterns of pathogen occurrences were evaluated using an immunoassay for Campylobacter spp., a formalin-ether concentration followed by observation of unstained slides for helminthes and trichome stains of fecal smears for protozoans. Specimens were examined microscopically using 100, 400 and 1000x magnification.

Results: Prevalence of Ascaris lumbricoides, Campylobacter spp., Giardia duodenalis, Entamoeba histolytica/E. dispar and Trichuris trichiura were $55.1 \%, 30.8 \%, 21.5 \%, 19.8 \%$ and $19.4 \%$, respectively. Overall, the prevalence of at least one intestinal pathogen was $85.5 \%$. Multi-infections were found in $43 \%$ of the children harboring pathogens.

Conclusions: Infections with Campylobacter spp., E. histolytica/E. dispar, T. trichiura and G. duodenalis were closely associated with the presence of co-infection with A. lumbricoides. T. trichiura infection was related to co-infection with A. lumbricoides and Campylobacter spp. Infections with G. duodenalis and T. trichiura were related to co-infections with either Campylobacter spp. or E. histolytica/E. dispar. The prevalence of multi-gastrointestinal infections with helminthes, protozoans and Campylobacter spp. in children was found to be related to age and gender.
\end{abstract}

Key words: Guatemala, diarrhoea, helminthes, protozoans, Campylobacter

J Infect Developing Countries 2009; 3(3):229-234.

Received 15 July 2008 - Accepted 3 February 2009

Copyright $\odot 2009$ Jensen et al. This is an open-access article distributed under the Creative Commons Attribution License, which permits unrestricted use, distribution, and reproduction in any medium, provided the original work is properly cited.

\section{Introduction}

Contaminated drinking water and soil and the lack of feces treatment are significant risk factors in the transmission of gastrointestinal pathogens [1,2]. Pathogens observed in multi-infections share the similar fecal-oral route of transmission, have similar age profiles, and are related to behavioral and occupational traits that increase their exposure to humans [3]. Under these conditions, multi-infections of helminths, protozoa and/or bacteria may be coincidental or enhance each other's ability to become established as pathogens in the gastrointestinal tract $[4,5]$.

To better understand the risk factors associated with multi-gastrointestinal infections in children, a prevalence study was conducted in two communities in the Guatemalan highlands and three riparian communities. The study evaluated the prevalence of multi-infections with Ascaris lumbricoides, Trichuris trichiura, Giardia duodenalis, Entamoeba histolyticalE. dispar and Campylobacter spp. in Guatemalan children.

\section{Materials and methods}

Characteristics of the communities studied

The study area included two communities in Guatemala, i.e., Santa Maria de Jesus and La Mano de Leon, which are located at the 4,500 $\mathrm{m}$ level in the mountains around Antigua and three riparian communities, El Esol, Chichipute, and Rio Dulce, situated on the banks of the Rio Dulce River. The five communities were chosen at random from the surrounding villages. Fecal samples were obtained during patient visits to field clinics. Each village was suspect for soil-transmitted gastrointestinal helminths and water-borne protozoans and bacteria. 
Table 1. Prevalence of single pathogens in children.

\begin{tabular}{|c|c|c|c|c|c|}
\hline & \multicolumn{4}{|c|}{$\begin{array}{l}\text { Number infected (\%) } \\
\text { Age Groups (yrs) }\end{array}$} & \\
\hline Male Pathogens & $0-4$ & $5-8$ & $9-12$ & Total & \\
\hline A. lumbricoides & $12(8.57)^{\mathrm{a}}$ & $6(4.29)$ & $5(3.57)$ & $23(16.43)$ & \\
\hline T. trichuris & $1(0.71)$ & $4(2.86)$ & $0(0.00)$ & $5(3.57)$ & \\
\hline E. histolytica/E. dispar & $2(1.43)$ & $1(0.71)$ & $0(0.00)$ & $3(2.14)$ & \\
\hline G. lamblia & $9(6.43)$ & $5(3.57)$ & $0(0.00)$ & $14(10.00)$ & \\
\hline Campylobacter spp. & $13(9.29)$ & $2(1.43)$ & $1(0.71)$ & $16(11.43)$ & \\
\hline Total & $37(26.43)^{b}$ & $18(12.86)^{b}$ & $6(4.29)$ & $61(43.57)$ & \\
\hline Female Pathogens & $0-4$ & $5-8$ & $9-12$ & Total & $\overline{\text { All }}$ \\
\hline A. lumbricoides & $17(12.14)^{\mathrm{a}}$ & $11(7.86)^{\mathrm{a}, \mathrm{c}}$ & $12(8.57)^{\mathrm{a}, \mathrm{c}}$ & $40(28.57)^{\mathrm{c}}$ & $63(45.00)$ \\
\hline T. trichuris & $1(0.71)$ & $1(0.71)$ & $0(0.00)$ & $2(1.43)$ & $7(5.00)$ \\
\hline E. histolytica/E. dispar & $5(3.57)$ & $4(2.86)$ & $1(0.71)$ & $10(7.14)^{\mathrm{c}}$ & $13(9.29)$ \\
\hline G. lamblia & $6(4.29)$ & $4(2.86)$ & $0(0.00)$ & $10(7.14)$ & $24(17.14)$ \\
\hline Campylobacter spp. & $6(4.29)$ & $8(5.71)$ & $3(2.14)$ & $17(12.14)$ & $33(23.57)$ \\
\hline Total & $36(25.71)^{b}$ & $28(20.00)^{b, c}$ & $16(11.43)^{\mathrm{c}}$ & $79(56.43)$ & $140(100.00)$ \\
\hline
\end{tabular}

${ }^{a} A$. Lumbricoides was significantly higher than other infections, $\mathrm{P}<0.05$

${ }^{b}$ Infections were significantly higher in 0-4 and 5-8 yr-old males, $\mathrm{P}<0.05$.

Infections in females were significantly higher than those in males,

In comparisons between data collected within each of the two highland and the three riparian communities, differences of muti-infection patterns could not be measured due to the small sample sizes of each age group. The two geographical areas were similar in that their economies were based on agricultural activities and they both had open sewer systems with poor sanitation practices and untreated drinking water. They differed with respect to diet: the riparian communities supplemented their diets with fish, which contrasted the mainly vegetable diet of the highland communities.

Diarhoea specimens from 289 children aged 0 to 12 years old were collected and analyzed for pathogens and the results were pooled. Diarrhoeal stools were obtained from patients with abdominal symptoms in order to increase the chances of identifying Campylobacter spp. infections along with helminth and protozoan infections. Diarrhoea was defined as three or more loose stools in a 24-hour period. A limitation in the data collected was the fact that the 0-4 age group did not contain enough participants to be broken down into multiple groups of 4-6 months of age and thus represents the most heterogeneous group of patients in the study.

\section{Examination of feces for pathogens}

Fecal analysis was restricted to five pathogens (A. lumbricoides, Campylobacter spp., E. histolyticalE. dispar, G. duodenalis and T. trichiura) based on the availability of diagnostic tests. To determine the presence of protozoan parasites, a smear of each fecal sample was trichrome-stained and examined microscopically using 1000x magnification. Fecal preparations (formalin-ether concentrations) were prepared and examined for the presence of helminth eggs using 100x and 400x magnification. Campylobacter spp. antigens were identified using an enzyme-linked immunosorbent assay (ELISA; Remel, Lenexa, KS). No attempt was made to concurrently assess the prevalence of other bacteria and parasites.

\section{Committee approval}

The present study is part of a research project entitled "Survey of human pathogens in Guatemala" and was approved by the Institutional Review Board and the Health Professions Division Research Committee of Nova Southeastern University. Informed consent was obtained from each patient's parent or guardian and, following diagnosis, the children were treated for observed infections. 
Table 2. Prevalence of two pathogens in children.

\begin{tabular}{|c|c|c|c|c|c|}
\hline (a) & & $\begin{array}{l}\text { lber infected } \\
\text { e groups (yr }\end{array}$ & & & \\
\hline Male co-pathogens & $0-4$ & $5-8$ & $9-12$ & Total & all \\
\hline A.l. + E.h. & $1(1.35)$ & $3(4.06)$ & $1(1.35)$ & $5(6.76)$ & \\
\hline A.l. + G.d. & $1(1.35)$ & $1(1.35)$ & $1(1.35)$ & $3(4.06)$ & \\
\hline A.l. + C.spp. & $5(6.76)$ & $2(2.70)$ & $2(2.70)$ & $9(12.16)$ & \\
\hline A.l. + T.t. & $2(2.70)$ & $3(4.06)$ & $2(2.70)$ & $7(9.46)$ & \\
\hline T.t. + E.h. & $0(0.00)$ & $1(1.35)$ & $0(0.00)$ & $1(1.35)$ & \\
\hline T.t. + G.d. & $1(1.35)$ & $1(1.35)$ & $0(0.00)$ & $2(2.70)$ & \\
\hline T.t. + C.spp. & $0(0.00)$ & $0(0.00)$ & $0(0.00)$ & $0(0.00)$ & \\
\hline G.d. + E.h. & $2(2.70)$ & $1(1.35)$ & $0(0.00)$ & $3(4.06)$ & \\
\hline G.d. +C.spp. & $3(4.06)$ & $3(4.06)$ & $0(0.00)$ & $6(8.11)$ & \\
\hline E.h. +C.spp. & $1(1.35)$ & $0(0.00)$ & $0(0.00)$ & $1(1.35)$ & \\
\hline Total & $16(21.62)^{\mathrm{a}}$ & $15(20.28)^{\mathrm{a}}$ & $6(8.10)$ & $37(50.0)$ & \\
\hline Female co-pathogens & $0-4$ & $5-8$ & $9-12$ & Total & all \\
\hline A.l. +E.h. & $1(1.35)$ & $4(5.41)$ & $6(8.11)$ & $11(14.86)$ & $16(21.62)^{\mathrm{b}}$ \\
\hline A.l. + G.d. & $3(4.06)$ & $0(0.00)$ & $0(0.00)$ & $3(4.06)$ & $6(8.11)$ \\
\hline A.l. +C.spp. & $6(8.11)$ & $2(2.70)$ & $1(1.35)$ & $9(12.16)$ & $18(24.32)^{\mathrm{b}}$ \\
\hline A.l. + T.t. & $1(1.35)$ & $3(4.06)$ & $1(1.35)$ & $5(6.76)$ & $12(16.22)^{b}$ \\
\hline T.t. + E.h. & $0(0.00)$ & $0(0.00)$ & $0(0.00)$ & $0(0.00)$ & $1(1.35)$ \\
\hline T.t. + G.d. & $0(0.00)$ & $0(0.00)$ & $0(0.00)$ & $0(0.00)$ & $2(2.70)$ \\
\hline T.t. + C.spp. & $0(0.00)$ & $0(0.00)$ & $1(1.35)$ & $1(1.35)$ & $1(1.35)$ \\
\hline G.d. + E.h. & $1(1.35)$ & $0(0.00)$ & $0(0.00)$ & $1(1.35)$ & $4(5.41)$ \\
\hline G.d. + C.spp. & $2(2.70)$ & $0(0.00)$ & $0(0.00)$ & $2(2.70)$ & $8(10.81)$ \\
\hline E.h. +C.spp. & $0(0.00)$ & $2(2.70)$ & $3(4.06)$ & $5(6.76)$ & $6(8.11)$ \\
\hline Total & $14(18.92)$ & $11(14.86)$ & $12(16.22)$ & $37(50.00)$ & $74(100.00)$ \\
\hline
\end{tabular}

(A.l:: Ascaris lumbricoides, T.t.: Trichuris trichiura, E.h.: Entamoeba histolyticalE. dispar, G.d.: Giardia duodenalis, C.sp.: Campylobacter species)

${ }^{\mathrm{a}}$ Co-infections were significantly higher in $0-4$ and $5-8$ yr-old males, $\mathrm{P}<0.05$.

${ }^{\mathrm{b}}$ A. lumbricoides + E. histolyticalE. dispar, A. lumbricoides + Campylobacter $\mathrm{sp}$. and $A$.

lumbricoides $+T$. trichiura were the most prevalent co-infections in males and females, $\mathrm{P}<0.05$.

\section{Statistical analysis}

Adjusted odds ratios and $95 \%$ confidence intervals were computed for estimates of associations between enteropathogens, and McNemar's test was used to compute P-values between co-infections of the samples [6].

\section{Results}

Pathogens were identified from 247 (85.5\%) of 289 diarrhoeal stools. One hundred and thirty-six specimens contained A. lumbricoides (55.1\%), 76 Campylobacter spp. (30.8\%), 53 G. duodenalis (21.5\%), 49 E. histolytica/E. dispar (19.8\%) and 48 T. trichiura $(19.4 \%)$. Of the 247 infected patients, 140 had only one pathogen; 70 with helminthes (50.0\%), 37 with protozoans $(26.43 \%)$ and 33 with Campylobacter sp (23.57\%) were also observed (Table 1). From the 107 patients with multiinfections, $74(30.0 \%)$ had two or more pathogens; $27(10.9 \%)$ had three or more pathogens; and six
(2.4\%) had four pathogens. In patients with two or more pathogens, helminth infections (41.1\%) prevailed over protozoan (32.7\%) and Campylobacter spp. (26.2\%) infections.

The most common co-infections were with either A. lumbricoides or Campylobacter spp. (Table 2). The most prevalent co-infections were $A$. lumbricoides + E. histolyticalE. dispar, A. lumbricoides + Campylobacter spp. and A.lumbricoides $+T$. trichiura. Total co-infections were highest in 0- to 4- and 5- to 8-yr-old males and were consistently lower throughout the female age groups. The overall prevalence of co-infections in males and females were the same. Of all the coinfections, A. lumbricoides was the only one that was significantly associated with the other four pathogens 
Table 3. Analysis of pathogens in co-infections of children.

Pathogen 1 vs. pathogen 2

Ascaris lumbricoides vs.

Campylobacter spp.

Entamoeba histolytica/E. dispar

Giardia duodenalis

Trichuris trichiura

Campylobacter sp. vs.

Ascaris lumbricoides

$0.417^{\mathrm{a}}$

Entamoeba histolytica/E. dispar

Giardia duodenalis

Trichuris trichiura

Entamoeba histolytica/E. dispar vs.

Ascaris lumbricoides

Campylobacter spp.

Trichuris trichiura

Giardia duodenalis vs.

Ascaris lumbricoides

Campylobacter spp.

Entamoeba histolytica/E. dispar

Trichuris trichiura $2.400^{\mathrm{a}}$

$3.273^{\mathrm{a}}$

$3.286^{\mathrm{a}}$

$10.000^{\mathrm{a}}$ $0.306^{\mathrm{a}}$

0.778

1.438

1.733

$0.304^{\mathrm{a}}$

1.286

$2.083^{\mathrm{a}}$

$2.133^{\mathrm{a}}$

$0.480^{\mathrm{a}}$

0.696

1.286
$95 \% \mathrm{Cl}$

1.282-4.718

1.630-7.128

1.775-6.472

1.615-38.481
$0.212-0.780$

0.700-2.392

1.009-4.551

1.112-4.239

0.140-0.614

$0.418-1.428$

$0.727-2.911$

$0.885-3.520$

Trichuris trichiura vs.

Ascaris lumbricoides

$0.100^{\mathrm{a}}$

0.026-0.277

Campylobacter spp.

$0.469^{\mathrm{a}}$

0.236-0.891

Giardia duodenalis

0.778

0.358-1.655

Entamoeba histolytica/E. dispar

0.577

$0.284-1.131$ 
Table 4. Prevalence of three pathogens in children.

\begin{tabular}{|c|c|c|c|c|c|}
\hline \multicolumn{6}{|c|}{$\begin{array}{l}\text { Number infected }(\%) \\
\text { Age groups (yrs) }\end{array}$} \\
\hline Male multi-pathogens & $0-4$ & $5-8$ & $9-12$ & Total & \\
\hline A.l. + T.t. + C.sp. & $1(3.70)$ & $1(3.70)$ & $0(0.00) 2$ & $(7.41)$ & \\
\hline A.l. + T.t. + E.h. & $1(3.70)$ & $0(0.00)$ & $0(0.00)$ & $1(3.70)$ & \\
\hline A.l. + G.d. +E.h. & $0(0.00)$ & $0(0.00)$ & $0(0.00)$ & $0(0.00)$ & \\
\hline A.l. + E.h. + C.sp. & $0(0.00)$ & $1(3.70)$ & $0(0.00)$ & $1(3.70)$ & \\
\hline T.t. + G.d. + E.h. & $0(0.00)$ & $1(3.70)$ & $0(0.00)$ & $1(3.70)$ & \\
\hline T.t. + G.d. + C.sp. & $0(0.00)$ & $1(3.70)$ & $0(0.00)$ & $1(3.70)$ & \\
\hline T.t. + E.h. + C.sp. & $0(0.00)$ & $0(0.00)$ & $0(0.00)$ & $0(0.00)$ & \\
\hline A.l. + T.t. + C.sp. & $3(11.10)$ & $0(0.00)$ & $1(3.70)$ & $4(14.81)^{b}$ & $6(22.22)$ \\
\hline A.l. + T.t. + E.h. & $0(0.00)$ & $0(0.00)$ & $2(7.41)$ & $2(7.41)$ & $3(11.10)$ \\
\hline A.l. + T.t. + G.d. & $2(7.41)$ & $0(0.00)$ & $0(0.00)$ & $2(7.41)$ & $4(14.81)$ \\
\hline A.l. + G.d. + C.sp. & $1(3.70)$ & $0(0.00)$ & $0(0.00)$ & $1(3.70)$ & $3(11.10)$ \\
\hline A.l. + G.d. +E.h. & $1(3.70)$ & $0(0.00)$ & $0(0.00)$ & $1(3.70)$ & $1(3.70)$ \\
\hline A.l. + E.h. + C.sp. & $0(0.00)$ & $2(7.41)$ & $2(7.41)$ & $4(14.81)^{\mathrm{b}}$ & $5(18.52)$ \\
\hline T.t. + G.d. + E.h. & $0(0.00)$ & $0(0.00)$ & $1(3.70)$ & $1(3.70)$ & $2(7.41)$ \\
\hline T.t. + G.d. + C.sp. & $0(0.00)$ & $1(3.70)$ & $0(0.00)$ & $1(3.70)$ & $2(7.41)$ \\
\hline T.t. + E.h. + C.sp. & $0(0.00)$ & $0(0.00)$ & $0(0.00)$ & $0(0.00)$ & $0(0.00)$ \\
\hline G.d. + E.h. + C.sp. & $0(0.00)$ & $1(3.70)$ & $0(0.00)$ & $1(3.70)$ & $1(3.70)$ \\
\hline
\end{tabular}

(A.l.: Ascaris lumbricoides, T.t.: Trichuris trichiura, E.h.: Entamoeba histolyticalE. dispar, G.d.: Giardia duodenalis, C.spp.: Campylobacter spp.)

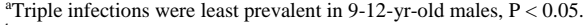

${ }^{\mathrm{b}}$ A. lumbricoides $+T$. trichiura + Camplybacter $\mathrm{sp}$. and A. lumbricoides + E. histolyticalE. dispar + Campylobacter spp. were significantly higher than other

triple infections for females over males, $\mathrm{P}<0.05$.

Table 5. Prevalence of four pathogens in children.

\begin{tabular}{|c|c|c|c|c|c|}
\hline \multirow[b]{2}{*}{ Male multi-pathogens } & \multicolumn{3}{|c|}{$\begin{array}{l}\text { Number infected }(\%) \\
\text { Age groups (yrs) }\end{array}$} & \multirow[b]{2}{*}{ Total } & \\
\hline & $0-4$ & $5-8$ & $9-12$ & & \\
\hline A.l. + T.t. + E.h. + C.sp. & $0(0.00)$ & $1(16.67)$ & $0(0.00)$ & $0(0.00)$ & \\
\hline A.l. + T.t. + E.h. + G.d. & $0(0.00)$ & $0(0.00)$ & $0(0.00)$ & $0(0.00)$ & \\
\hline A.l. + T.t. + G.d. + C.sp. & $0(0.00)$ & $0(0.00)$ & $0(0.00)$ & $0(0.00)$ & \\
\hline T.t. + G.d. + E.h. + C.sp. & $0(0.00)$ & $0(0.00)$ & $0(0.00)$ & $0(0.00)$ & \\
\hline Total & $0(0.00)$ & $1(16.67)$ & $0(0.00)$ & $1(16.67)$ & \\
\hline Female multi-pathogens & $0-4$ & $5-8$ & $9-12$ & Total & All \\
\hline A.l. + T.t. + E.h. + C.sp. & $0(0.00)$ & $1(16.67)$ & $1(16.67)$ & $2(33.33)$ & $3(50.00)$ \\
\hline A.l. + T.t. + E.h. + G.d. & $0(0.00)$ & $0(0.00)$ & $0(0.00)$ & $0(0.00)$ & $0(0.00)$ \\
\hline A.l. + T.t. + G.d. + C.sp. & $1(16.67)$ & $1(16.67)$ & $0(0.00)$ & $2(33.33)$ & $2(33.33)$ \\
\hline T.t. + G.d. + E.h. + C.sp. & $0(0.00)$ & $1(16.67)$ & $0(0.00)$ & $1(16.67)$ & $1(16.67)$ \\
\hline Total & $1(16.67)$ & $3(50.00)^{\mathrm{a}}$ & $1(16.67)$ & $5(83.33)^{b}$ & $6(100.00)$ \\
\hline
\end{tabular}

(A.l.: Ascaris lumbricoides, T.t.: Trichuris trichiura, E.h.: Entamoeba histolyticalE. dispar, G.d.: Giardia duodenalis, C.spp.: Campylobacter spp.)

${ }^{\text {a}}$ Four of the six multi-infections were found in the 5-8-year-old groups.

${ }^{b}$ Five of the six multi-infections were found in females. 
(Table 3). Campylobacter spp. was significantly associated with all pathogens except $E$. histolyticalE. dispar. E.histolyticalE. dispar + A. lumbricoides, $G$. duodenalis $+A$. lumbricoides, $T$. trichiura $+A$. lumbricoides and T. trichiura + Campylobacter spp. were significantly associated with each other.

Both males and females had more triple infections of $A$. lumbricoides $+T$. trichiura + Campylobacter spp. and A. lumbricoides $+E$. histolyticalE. dispar + Campylobacter spp. than other infection combinations (Table 4). Nine- to twelveyear-old males did not have triple infections. Females had the most infections with four pathogens (Table 5).

\section{Discussion}

Children living in both Guatemalan highland and riparian communities are infected soon after weaning and likely re-infected during the rest of their childhood. This prevalence of multi-infections is affected by malnutrition [7], by differences in the behavior of children, by irregular distributions of infecting stages in the environment, by differences in the ability to generate an adequate immunological response, by basic biological differences between parasites, and by host genetic differences [2]. Previous studies have shown that individuals with multiple infections tend to display higher intensities of infection than that expected for each infection separately [8,9]. Thus, infection by one of the pathogens may be influenced by concurrent or earlier infections with the other.

The use of patients with diarrhoeal stools in the absence of controls in the present study limits the analysis of the results of multi-infections associated with patients' exhibiting abdominal symptoms; and the absence of information on the presence of fever, bloody stools, or chronicity of diarrhoea further limits the results to patients with nonspecified abdominal symptoms. However, our study demonstrated that the extent of multi-gastrointestinal pathogen prevalence was different by gender and was strongly associated with age. Infants and young children were more likely to have multiple infections when compared to older children, a finding consistent with lifestyle differences. This coexistence of pathogens in children could have been influenced by the presence of malnutrition or a low immune state resulting in reduced host resistance to infection.

Reported pathogen prevalence rates are not always comparable due to the use of different research methods, i.e., the use of different diagnostic techniques, or selection of geographical locations, or socioeconomic patterns. Therefore, this high prevalence of co-infections emphasizes the need for more comprehensive analysis of stool samples for pathogens that relate to disease symptoms.

\section{References}

1. Booth M, Bundy DAP, Albonico M, Chwaya HM, Alawi KS, Savioli (1998) Associations among multiple geohelminth species infections in schoolchildren from Pemba Island. Parasitology 116: 85-93.

2. Drake LJ, Bundy DAP (2001) Multiple helminth infections in children: Impact and control. Parasitology 122: S73-S81.

3. Mahfouz AAR, El-Morshedy H, Farghaly A, Khalil A (1997) Ecological determinants of intestinal parasitic infections among pre-school children in an urban squatter settlement of Egypt. Journal of Tropical Pediatrics 43: 341344.

4. Raso G, Luginbuhl, Adjoua CA, Tian-Bi NT, Silue KD, Matthys , Vounatsou P, Wang Y, Dumas ME, Holmes E, Singer BH, Tanner M, N'Goran EK, Utzinger J (2004) Multiple parasite infections and their relationship to selfreported morbidity in a community of rural Cote d'Ivoire. International Journal of Epidemiology 33: 1092-1102.

5. Wakelin D (1986) Genetic and other constraints on resistance to infection with gastrointestinal nematodes. Transactions of the Royal Society of Tropical Medicine and Hygiene 80: 742-747.

6. Rosner B (2000) Fundamentals of Biostatistics. $5^{\text {th }}$ edition, Pacific Grove, California: Duxbury 792 pp.

7. Cox FEG (2001) Concomitant infections, parasites and immune responses. Parasitology 122: S23-S38.

8. Brooker S, Miguel EA, Moulin S, Luoba AI, Bundy DAP, Kremer M (2000) Epidemiology of single and multiple species of helminth infections among school children in Busia District, Kenya. East African Medical Journal 77: 157-161.

9. Needham C, Kim HT, Hoa NV, Cong LD, Michael, Drake , Hall A, Bundy DAP (1998) Epidemiology of soiltransmitted nematode infections in $\mathrm{Ha}$ Nam Province, Vietnam. Tropical Medicine and International Health 3: 904-912.

\section{Corresponding Author}

Harold E. Laubach

Department of Microbiology, College of Medical Sciences

Health Professions Division

Nova Southeastern University

3200 South University Drive

Fort Lauderdale, FL 33328

Phone 9542621303

Fax 9542621802

Email: harold@nsu.nova.edu

Conflict of interest: No conflict of interest is declared. 